\title{
Possibilidades e potencialidades técnico-táticas em diferentes tradicionais jogos/brincadeiras de bola com os pés \\ Technical-tactics possibilities and potentialities in different traditional ball games played with feet Posibilidades y potencialidades técnico-tácticas en diferentes juegos de pelota tradicionales que se juegan con los pies \\ *Alcides José Scaglia, *Vitor Hugo Silva Costa, *João Bosco Júnior, *Milton Shoiti Misuta, **João Cláudio Machado *Universidade Estadual de Campinas (Brazil), **Universidade Federal do Amazonas (Brazil)
}

Resumo. O estudo tem como objetivo investigar as possibilidades e diferentes potencialidades dos jogos que compõem a cultura

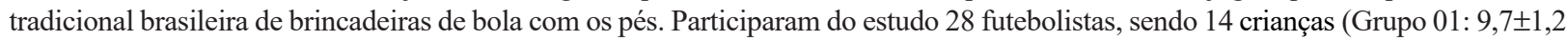
anos) e 14 universitários (Grupo 02: 21,1 $\pm 1,7$ anos). Os jogadores participaram de três jogos/brincadeiras de bola com os pés (Rebatida, Bobinho e Artilheiro). O desempenho dos jogadores foi analisado através do software Dvideow ${ }^{\circledR}$, que registrou as ações técnico-táticas realizadas por ambos grupos. Foi possível constatar que cada um dos jogos/brincadeiras de bola com os pés investigados, em meio ao seu processo de organização, apresentam as mesmas possibilidades técnico-táticas, independentemente do grupo a jogar, ao mesmo tempo em que estes díspares jogos proporcionaram diferentes potencialidades técnico-táticas. Portanto, o entendimento do processo de organizacional sistêmico dos jogos/brincadeiras de bola com os pés demonstra ser conhecimento fundamental para o treinador planejar e conduzir sessões de treino representativas e desafiadoras. O conhecimento sobre as possibilidades e potencialidades dos diversos jogos/ brincadeiras de bola com os pés, pertencentes à cultura do nosso futebol de rua, permitem aos treinadores implementar e acompanhar um processo de ensino centrado no aluno, pautado no jogo e inspirado na pedagogia da rua.

Palavras-chave: Futebol, Futebol de rua, Pedagogia do Jogo, Possibilidades, Potencialidades pedagógicas.

\begin{abstract}
This study aimed to investigate the possibilities and potentialities of different games which compose the traditional Brazilian culture of playing ball games with feet, highlighting its systemic organizational process. Twenty-eight male soccer players participated in the study, being 14 children (Group 01: 9,7 $\pm 1,2$ years) and 14 university students (Group 02: 21,1 $\pm 1,7$ years). The players performed three games played with their feet (Rebatida, Bobinho and Artilheiro). The players' performance was analyzed using the Dvideow ${ }^{\circledR}$ software, which recorded the technical-tactical actions performed by both groups. It was possible to highlight that each of the game investigated, respecting their own organization process, presented the same technical-tactical possibilities, regardless of the group of players, at the same time that these disparate games provided different technical-tactical potentialities. Therefore, understanding the systemic organizational process of ball games played with the feet proves to be extremely important for coaches' better plan and conduct representative and challenging training sessions. The knowledge about the possibilities and potentialities of several small games, belonging to the culture of our street football, allow coaches to implement and monitor a player-centered and game-based teaching and training process, inspired by street pedagogy.
\end{abstract}

Keywords: Soccer, Street football, Game Pedagogy, Possibilities, Pedagogical potentialities.

Resumen. El estudio tiene como objetivo investigar las posibilidades y el potencial de los diferentes juegos que conforman la cultura tradicional brasileña de jugar a la pelota con los pies, destacando su proceso organizativo sistémico. Participaron en el estudio 28

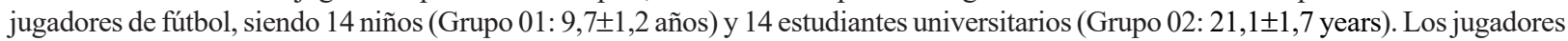
participaron en tres juegos de pelota con los pies (Rebatida, Rondo and Artilheiro). El rendimiento de los jugadores se analizó utilizando el software Dvideow ${ }^{\circledR}$, que registró las acciones técnico-tácticas realizadas por ambos grupos. Fue posible verificar que cada uno de los juegos investigados, en el medio de su proceso de organización, presenta las mismas posibilidades técnico-tácticas, independientemente del grupo de jugadores, al mismo tiempo que estos juegos dispares proporcionaban diferentes potencialidades técnico-tácticas. Por lo tanto, la comprensión del proceso organizativo sistémico de los juegos de pelota con los pies demuestra ser un conocimiento fundamental para que el entrenador planifique y realice sesiones de entrenamiento representativas y desafiantes. El conocimiento sobre las posibilidades y el potencial de los diversos juegos de pelota con los pies, pertenecientes a la cultura de nuestro fútbol callejero, permiten a los entrenadores implementar y monitorear un proceso de enseñanza centrado en el alumno, basado en el juego e inspirado en la pedagogía callejera.

Palabras clave: Fútbol, Fútbol callejero, Pedagogía del juego, Posibilidades, Potencial pedagógico.

\section{Introdução}

Com o passar dos anos, é cada vez mais difícil encontrar espaços apropriados para as crianças praticarem o futebol em contextos informais (Machado et al., 2017). As ruas foram sendo tomadas pelos carros e a violência foi se apropriando dos demais espaços das grandes cidades e dos locais genuínos de prática lúdica, além da formação das crianças e

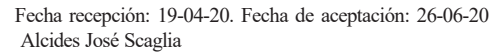

jovens ser cada vez mais institucionalizada e cerceadora da liberdade (Fabiani, 2016). Com isso, os ambientes formais de aprendizagem (ex.: escolas de futebol) ganharam espaço em decorrência desse desencaixe social (Giddens, 1991), tornando-se muitas vezes o lugar em que a criança tem o primeiro contato com a modalidade (Machado et al., 2019; Scaglia, 2014). Todavia, evidências têm demonstrado que esses ambientes formais de aprendizagem proporcionam aos jogadores contextos de prática descontextualizados, através de tarefas de treino, que contemplam a reprodução de gestos técnicos de maneira fragmentada (Chow, 2013; Galatti et al., 2014; Scaglia, 2014b), com menor tempo de fruição do jogo (Ford et al., 2010), optando por práticas deliberadas em detrimentos 
aos jogos livres e deliberados. Diferentemente, os contemporâneos estudos em Pedagogia do Esporteafirmam ser aconselhado que o treinador proponha aos seus jogadores ambientes desafiadores e prazerosos, que resgatem elementos centrais do futebol de rua, levando-os a explorarem o contexto de jogo em busca soluções aos problemas que emergem em decorrência das constantes relações de cooperação e oposição entre os jogadores (Bettega et al., 2018; Caldeira et al., 2019; Chow \& Atencio, 2014; Kirk \& MAchapgail, 2002; Scaglia, 2017; Sierra-Díaz, 2019).

Com isso, entendendo toda a riqueza apresentada pela vasta quantidade e diversidade de jogos/brincadeiras de bola com os pés para a aprendizagem de jovens futebolistas, destaca-se a importância de treinadores proporcionarem aos jogadores ambientes ricos de jogo e aprendizagem que venham a resgatar elementos centrais do futebol de rua (Garganta, Guilherme, Barreira, Brito \& Rebelo, 2013; Scaglia, 2011; Machado, Thiengo \& Scaglia, 2017; Machado, Barreira, Galatti, Chow, Garganta, Scaglia, 2019). Neste sentido, temos defendido, ao longo dos anos de investigação (Scaglia, 2011; Machado et al., 2017; Machado et al., 2019; Scaglia, 2014; Belozo \& Scaglia, 2017), que o chamado futebol de rua não pode ser entendido apenas em função do local onde este é jogado, mas sim em decorrência do espaço lúdico, ambiente de aprendizagem informal, em que uma gama de jogos/ brincadeiras são realizados com expressa e pretensa liberdade, também nos campinhos de terra batida, na praia, ou em qualquer outro lugar disponível e/ou adaptável para sua prática (Scaglia, 2011, 2014; Machado et al., 2019), evidenciado o que denominamos pedagogia da rua (Scaglia, 2011, 2014; Freire, 2003).

Diversos estudos destacam que um maior engajamento nesses espaços informais de prática, geram contextos de aprendizagem (Scaglia, 2011; Machado et al., 2019; Fonseca \& Garganta, 2006), e contribuem para o desenvolvimento das habilidades perceptivas, decisionais e motoras (Roca et al., 2012; Ford et al., 2009), bem como impulsionam uma prática sistemática posterior ao longo da carreira do esportista (Scaglia, 2011; Côté et al., 2013). Além disso, o futebol de rua, explicitando a pedagogia da rua, tem se mostrado historicamente importante na construção de um jogar futebol no Brasil, justificado a partir da cultura futebolística tecida num ambiente de jogo, em meio a uma vasta e miscigenada cultura lúdica (Scaglia, 2011; Freire, 2003).

Importante destacar que defendemos há tempos que qualquer modalidade esportiva, antes de tudo, se trata de um jogo e que ambos são compreendidos como sistemas complexos (Freire, 2002, 2003b; Scaglia, 2005, 2011), dotados de características como imprevisibilidade e aleatoriedade, ordem e desordem, organização e interação (Scaglia et al., 2013). Nesse sentido, o ensino deve privilegiar uma aprendizagem pautada em uma pedagogia do jogo, valorizando sua complexidade sistêmica, pois o jogo exigirá uma teia complexa de ações, gestos e intenções na busca de soluções para os problemas criados em seu contexto (Reverdito et al., 2009; Leonardo et al., 2009; Scaglia et al., 2013). Para isso, Scaglia (2017) propõe a utilização da Pedagogia do Jogo enquanto modelo metodológico para o ensino dos jogos esportivos coletivos, evidenciada pelo entendimento do processo organizacional sistêmico dos jogos. O autor destaca que para se entender o processo organizacional sistêmico do jogo, deve-se conhecer suas estruturas padrões básicas (regras, condições externas, jogadores, indissociáveis de seus esquemas motrizes) que interagem entre si, produzindo emergências, isto é, potencializando a aprendizagem dos jogadores, em meio às possibilidades.

No entanto, considerando uma das principais estruturas básicas do jogo, o jogador, devemos respeitar seus constrangimentos individuais (dinâmicas intrínsecas), logo é necessário que o treinador adapte os níveis de dificuldade das suas tarefas de treino, de modo a proporcionar desafios suficientemente apropriados aos seus jogadores, proporcionando condições para que mais facilmente o jogador se entregue ao jogo, evidenciando um estado de jogo (Machado et al., 2019b; Belozo \& Scaglia, 2017). Essa é justamente a condição do risco em que o jogador se apresenta ao jogo que potencializará sua aprendizagem.

Todavia, essa adequação planejada e sistematizada é possível à medida que o treinador, manipulando as regras funcionais e estruturais dos jogos frente aos desafios impostos pelas condições externas, anteveja as emergências advindas da interação entre as estruturas básicas, que regem o padrão de organização dos jogos (Scaglia, 2011, 2017; Scaglia et al., 2013). Em nosso particular, sendo mais específico, compreender o processo organizacional sistêmico dos diferentes jogos/brincadeiras de bola com os pés permite a manipulação das possibilidades de ensino evidentes do jogo, de modo a potencializar a aprendizagem dos conteúdos latentes em seus jogadores. Essa ação pedagógica respeita a essência do futebol de rua, e evidencia as bases da pedagogia da rua (Scaglia, 2011, 2014, 2017; Machado et al., 2019).

Portanto, o objetivo desse estudo foi investigar as possibilidades de ensino e potencialidades de aprendizagem técnico-táticas de diferentes jogos/brincadeiras de bola com os pés (Bobinho, Rebatida e Artilheiro), que fazem parte da tradicional cultura do futebol de rua no Brasil, em meio ao seu processo organizacional sistêmico.

\section{Material e Método}

Essa pesquisa teve seu delineamento marcado a partir dos conceitos de possibilidades e potencialidades. Possibilidades diz respeito a todo o conteúdo evidente no jogo, neste particular as ações técnico-táticos, evidenciando conteúdos passíveis de ensino. Já as potencialidades são os conteúdos latentes, ou seja, dependem do modo como as estruturas padrões básicas do jogo (regras, condições externas, jogadores, indissociáveis de seus esquemas motrizes) irão interagir umas com as outras, desencadeando o seu processo de organização. Nesse sentido, é possível afirmar que, dependendo de quem está a jogar (jogadores e seus esquemas motrizes), o mesmo jogo (regras e condições externas) pode apresentar a emergência de diferentes potencialidades de aprendizagem. É importante destacar que devemos compreender estes conceitos (possibilidades e potencialidades) na perspectiva da complexidade, pois eles são tecidos juntos, logo são sempre interdependentes e complementares.

Outro aspecto a se destacar em nossa metodologia é o 
fato de nos valermos dos constructos científicos produzidos por Ibañez $(2000,2002)$ relativos aos conteúdos do jogo delimitados para esse estudo. Logo, assumimos que todos os gestos técnicos são eminentemente dependentes da tática, e todas as ações táticas não ocorrem desassociadas das técnicas corporais, superando uma visão limitadora de se pensar apenas em fundamentos técnicos e/ou ações táticas como movimentos básicos que independem dos seus contextos de ação e tomadas de decisão.

\section{Participantes}

Participaram do estudo 28 jogadores de futebol, sendo 14 crianças recrutadas de uma escola de futebol de um projeto social da Universidade Estadual de Campinas (UNICAMP)

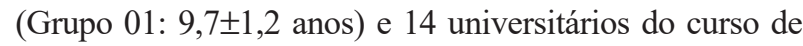
Ciência do Esporte da UNICAMP (Grupo 02: 21,1 1, 7 anos). Uma breve explicação dos procedimentos do estudo foi feita, participando apenas os jogadores que entregaram os Termos de Consentimento Livres e Esclarecidos e os Termos de Assentimentos assinados, previamente aprovados pelo Comitê de ética em Pesquisa da UNICAMP (CAEE 78577717.3.0000.5404).

\section{Desenho Experimental}

Três jogos/brincadeiras de bolas com os pés foram realizados (tabela 01) para ambos os Grupos: i) Bobinho; ii) Rebatida e iii) Artilheiro.

\begin{tabular}{|c|c|c|c|}
\hline $\begin{array}{c}\text { Jogo/Brincadeira } \\
\text { Condições }\end{array}$ & Bobinho & Rebatida & Artilheiro \\
\hline Espaço & Campo de $8 \mathrm{~m} \times 8 \mathrm{~m}$. & $\begin{array}{c}\text { Uma baliza; } \\
\text { Metade do campo. }\end{array}$ & Campo de futebol Society. \\
\hline Jogadores & $\begin{array}{l}6 \text { jogadores na roda vs } 1 \\
\text { bobo. }\end{array}$ & $2 \times 2$ & $2 \times 2$ \\
\hline Regras & $\begin{array}{c}2 \text { toques na bola aos } \\
\text { jogadores que estão na } \\
\text { roda; } \\
\text { Para sair do bobo, basta } \\
\text { tocar na bola; } \\
\text { Passe realizado para } \\
\text { fora da área de jogo, } \\
\text { troca de bobo. }\end{array}$ & $\begin{array}{c}\text { Cada jogador tem } \\
\text { direito a } 3 \text { finalizações; } \\
\text { Goleiro não pode sair } \\
\text { da área para pegar a } \\
\text { bola; }\end{array}$ & $\begin{array}{l}\text { Máximo de } 2 \text { toques na bola; } \\
\text { Ao sair gol, deve-se haver a } \\
\text { troca entre goleiro e atacante; } \\
\text { Se o adversário interceptar e } \\
\text { mesmo assim a bola passar } \\
\text { para o ataque, o atacante } \\
\text { ganha mais um toque; } \\
\text { A equipe de ataque ganha um } \\
\text { pênalti caso finalize na trave. }\end{array}$ \\
\hline Pontuação & - & $\begin{array}{c}\text { Gol direto }=1 \text { ponto; } \\
\text { Após a rebatida em: } \\
\text { Escanteio: } 2 \text { pontos; } \\
\text { Trave }=5 \text { pontos } \\
\text { Travessão }=10 \text { pontos } \\
\text { Ângulo }=15 \text { pontos }\end{array}$ & $1 \mathrm{gol}=1$ ponto \\
\hline Tempo de jogo & 4 minutos. & - & $\begin{array}{l}4 \text { à } 8 \text { minutos, vencendo a } \\
\text { equipe fizer } 4 \text { gols. }\end{array}$ \\
\hline
\end{tabular}

\section{Análise das possibilidades técnico-táticas}

Em cada jogo/brincadeira de bola com os pés, o desempenho técnico-tático dos jogadores foi quantificado considerando a quantidade de ocorrências. Para isso, o software Dvideow® foi usado para o registro de cada ação realizada (Figueroa, Leite, \& Barros, 2003). Foram adotados para análise neste estudo as seguintes ações técnico-táticas: passe, lançamento, domínio, condução, finalização, desarme, interceptação, escanteio e disputa. Essas ações estiveram presentes em estudos prévios (Lizana, 2013; Ferreira, 2014; Belozo, 2015; Grandim, 2015).

\section{Análise das potencialidades técnico-táticas}

Em decorrência da lógica interna de cada jogo, buscamos um conjunto de indicadores para analisar as diferentes potencialidades técnico-táticas evidenciadas pelos diferentes grupos (Grupo 01 e Grupo 02), em cada um dos jogos/ brincadeiras de bola com os pés. Nos jogos de bobinhos, para analisar as potencialidades que emergiram destes jogos em cada um dos grupos, os seguintes indicadores foram utilizados: (a) duração da unidade de observação (i.e. tempo em que os grupos conseguem manter a posse da bola, até que ocorra um passe errado ou que o «bobo» consiga interceptar o passe); (b) número de toques na bola (i.e., quantidade de toques na bola efetuada por cada jogador que participa da referida unidade de observação); (c) número de passes realizados (i.e., quantidade de passes certos realizados); (d) número de jogadores que participam da unidade de observação (i.e., quantidade de jogadores que tocam na bola); (e) toques na bola por jogador (i.e., quantidade de toques na bola efetuada por cada jogador que participa da unidade de observação); (f) dinâmica de troca de passes (i.e., rácio entre a quantidade de toques na bola e a duração da unidade de observação).

Já na Rebatida, na tentativa de analisar as potencialidades emergentes desses jogos, os seguintes indicadores foram utilizados: (a) finalização certa (i.e., que acertaram o alvo); (b) finalização errada (i.e., que não acertaram o alvo); (c) número de rebatidas (i.e., quantidade de rebatidas geradas a partir das finalizações); (d) duração rebatida (i.e., o tempo de duração dos jogos de 2x1 que se iniciavam com a rebatida); (e) toques na bola (i.e., quantidade de toques na bola efetuada pelos jogadores nos jogos de 2x1, que se iniciavam após a rebatida); (f) passes realizados (i.e., quantidade de passes realizados nos jogos de 2x1, que se iniciavam após a rebatida); (g) disputas realizadas (i.e., quantidade de situações de $1 x 1$ que emergiram nos jogos, que se iniciavam após a partida).

Nos jogos de Artilheiro, por sua vez, para analisar as potencialidades destes jogos, os seguintes indicadores foram utilizados: (a) duração da unidade de observação (i.e., do momento que ocorre o lançamento do goleiro até a finalização ou a perda da posse de bola); (b) interceptação (i.e., retomada de bola realizada pelo jogador de ataque, após o lançamento do goleiro); (c) eficácia ofensiva (i.e., gols marcados/unidades de observação); (d) duração total do jogo. Todas essas ações também foram registradas através do software Dvideow ${ }^{\circledR}$ (Figueroa, Leite, \& Barros, 2003).

\section{Análise Estatística}

Foram realizados os testes de Komolgorov-Smirnov e de Levene para verificar a normalidade e homogeneidade das variâncias, respectivamente, dos dados e uma estatística descritiva para apontar as características de desempenho técnico-tático dos jogadores nos diferentes jogos/ brincadeiras realizados. A análise do desempenho técnicotático dos jogadores foi realizada considerando: (a) tipos de jogos (jogos de Bobinho, Rebatida e Artilheiro). O Teste de Kruskal-Wallis e o post-hoc Teste de Dunn's foram aplicados para verificar as diferenças entre os jogos aplicados; (b) para fins de avaliação, considerando a faixa etária (crianças e universitários), foi aplicado o Teste de Mann-Whitney em cada um dos jogos. Todo tratamento estatístico foi realizado no programa SPSS 20.0, adotando-se o nível de significância de $5 \%(\mathrm{p}<.05)$. 


\section{Resultados}

\section{Possibilidades técnico-táticas}

A Tabela 2 apresenta os resultados do desempenho técnico-tático dos grupos em cada um dos jogos/brincadeiras de bola com os pés. Há um indicativo de que cada jogo/ brincadeira proporcionou as mesmas possibilidades técnico-táticas para ambos os grupos, uma vez que os levantamentos realizados apontam que os conteúdos evidentes estiveram presentes tanto para o Grupo 1 quanto para o Grupo 2. No Bobinho, houve uma maior prevalência em passes certos (Grupo 01: $p=.012$; Grupo 02: $p=.002$ ) $\mathrm{e}$ domínio de bola (Grupo 01: $p=.008$; Grupo 02: $p=.015$ ), evidenciando o conteúdo evidente de manutenção da posse de bola. Já nos jogos de Rebatida e de Artilheiro, houve uma prevalência de finalizações, enquanto que nos jogos de Bobinho não ocorreram tais ações técnico-táticas. Além disso, os jogos de Rebatida e Artilheiro possibilitaram a realização de ações técnico-táticas de condução e lançamento, evidenciando assim o conteúdo evidente de progressão ao alvo.

Tabela 2.

Desempenho técnico-tático do Grupo 01 (Crianças) e do Grupo 02 (Universitários) nos diferentes jogos de bola com os pés.

\begin{tabular}{|c|c|c|c|c|c|c|}
\hline \multirow[b]{2}{*}{ Indicadores } & \multicolumn{3}{|c|}{ Grupo o1 } & \\
\hline & $\begin{array}{c}\text { Bobinho } \\
\text { Média } \pm \text { DP }\end{array}$ & $\begin{array}{c}\text { Rebatida } \\
\text { Média } \pm D P\end{array}$ & $\begin{array}{l}\text { Artilheiro } \\
\text { Média } \pm D P P\end{array}$ & $\begin{array}{c}\text { Bobinho } \\
\text { Média } \pm \text { DP }\end{array}$ & $\begin{array}{c}\text { Rebatida } \\
\text { Média } \pm \text { DP }\end{array}$ & $\begin{array}{l}\text { Artilheiro } \\
\text { Média } \pm D P\end{array}$ \\
\hline Passe certo & $17 \pm 3,559^{\#}$ & $3,50 \pm 1,291^{\#}$ & Não houve & $26,50 \pm 8,435^{\#}$ & $1,50 \pm 1,915^{\#}$ & Não houve \\
\hline Domínio certo & $10,71 \pm 3,592^{\text {si }}$ & $4,25 \pm 1,708^{*}$ & $2,33 \pm 2,517^{\$}$ & $10,75 \pm 5,175^{\text {s }}$ & $2,00 \pm 1,414^{\#}$ & $1,75 \pm 2,062^{\mathrm{s}}$ \\
\hline Disputa & $1,00 \pm 1,155$ & $1,50 \pm 0,577$ & Não houve & $0,88 \pm 0,835$ & Não houve & Não houve \\
\hline Interceptação & $1,29 \pm 1,113$ & $1,00 \pm 0,816$ & $2,33 \pm 2,082$ & $2,25 \pm 1,165$ & $0,75 \pm 0,957$ & $1,00 \pm, 0,816$ \\
\hline Finalização certa & Não houve & $5,25 \pm 1,708$ & $5,67 \pm 2,309$ & Não houve & $6,00 \pm 0,816$ & $2,50 \pm 1,9015$ \\
\hline Finalização errada & Não houve & $3,00 \pm 2,449$ & $1,00 \pm 0,000$ & Não houve & $1,00 \pm 0,000$ & $1,75 \pm 1,708$ \\
\hline Escanteio & Não houve & $0,50 \pm 0,535$ & Não houve & Não houve & $0,50 \pm 0,577$ & Não houve \\
\hline Condução & Não houve & $1,50 \pm 0,577$ & $1,00 \pm 0,00$ & Não houve & $1,75 \pm 0,500$ & $1,755 \pm 1,500$ \\
\hline Lançamento & Não houve & $2,25 \pm 4,500$ & $7,00 \pm 6,557$ & Não houve & $0,25 \pm 0,500$ & $4,50 \pm 3.873$ \\
\hline
\end{tabular}
Fonte: Os autores

\section{Potencialidades técnico-táticas}

Em relação às potencialidades técnico-táticas, foi possível constatar que os jogadores do Grupo 02 conseguiram gerir melhor os constrangimentos do jogo de Bobinho, apresentando uma quantidade maior de passes certos realizados $(p=.024)$ (Tabela 3). Além disso, os jogadores do Grupo 01 realizaram uma quantidade maior de toques na bola $(p=.004)$, enquanto que os jogadores do Grupo 02 apresentaram uma maior dinâmica de troca de passes $(p=$ $.038)$.

\begin{tabular}{|c|c|c|}
\hline Indicadores & $\begin{array}{c}\text { Grupo 01 } \\
\text { Média } \pm \text { DP }\end{array}$ & $\begin{array}{c}\text { Grupo 02 } \\
\text { Média } \pm \text { DP }\end{array}$ \\
\hline Duração da unidade de observação (s) & $10,97 \pm 11,26$ & $10,96 \pm 13,36$ \\
\hline Número de toques na bola & $9,12 \pm 7,33$ & $11,55 \pm 12,21$ \\
\hline Passes realizados & $17 \pm 3,559^{*}$ & $26,50 \pm 8,435^{*}$ \\
\hline Número de jogadores envolvidos & $5,96 \pm 4,40$ & $8,82 \pm 9,96$ \\
\hline Toques por jogador & $1,48 \pm 0,22^{*}$ & $1,29 \pm 0,23^{*}$ \\
\hline Dinâmica de troca de passes & $1,06 \pm 0,39^{*}$ & $1,25 \pm 0,38^{*}$ \\
\hline
\end{tabular}

Fonte: Os autores.

Já no jogo da Rebatida, foi possível constatar a ausência de disputas de bola no Grupo 02, enquanto que os jogadores do Grupo 01 apresentaram uma quantidade maior de disputas realizadas, indicando que os universitários, nestes jogos, conseguiram aproveitar melhor a superioridade numérica por meio de um jogo mais coletivo, o que pode ser evidenciado também pelo menor tempo de duração das rebatidas nesse grupo (Universitários), apesar desta diferença na duração não ser estatisticamente significativa.

\begin{tabular}{|c|c|c|}
\hline Indicadores & $\begin{array}{c}\text { Grupo 01 } \\
\text { Média } \pm \text { DP }\end{array}$ & $\begin{array}{c}\text { Grupo 02 } \\
\text { Média } \pm \text { DP }\end{array}$ \\
\hline Finalização certa & $5,25 \pm 1,708$ & $6,00 \pm 0,816$ \\
\hline Finalização errada & $3,00 \pm 2,449$ & $1,00 \pm 0,000$ \\
\hline Número de rebatidas & $0,62 \pm 0,71$ & $0,75 \pm 0,45$ \\
\hline Duração da rebatida (s) & $23,00 \pm 23,75$ & $14,07 \pm 13,23$ \\
\hline Toques na bola & $10,60 \pm 8,77$ & $11,08 \pm 11,67$ \\
\hline Passes realizados & $3,50 \pm 1,291$ & $1,50 \pm 1,915$ \\
\hline Disputas realizadas & $1,50 \pm 0,577$ & Não houve \\
\hline
\end{tabular}

No jogo de Artilheiro, não foi possível encontrar diferenças estatisticamente significativas para os indicadores utilizados. No entanto, é importante destacar que o jogo realizado pelos Universitários (Grupo 02) se encerrou com 04:05 minutos, após uma das equipes marcar quatro gols, enquanto que o jogo realizado pelo Grupo 01, encerrou-se aos 08 minutos, sem que uma equipe conseguisse marcar os quatro gols necessários para finalizar a partida.

\begin{tabular}{|c|c|c|}
\hline Indicadores & $\begin{array}{c}\text { Grupo 01 } \\
\text { Média } \pm \text { DP }\end{array}$ & $\begin{array}{c}\text { Grupo 02 } \\
\text { Média } \pm \text { DP }\end{array}$ \\
\hline Duração da unidade de observação (s) & $11,24 \pm 6,80$ & $9,00 \pm 4,90$ \\
\hline Interceptação & $2,33 \pm 2,082$ & $1,00 \pm, 0,816$ \\
\hline Eficácia ofensiva & $0.08+0.28$ & $0.27+0.46$ \\
\hline
\end{tabular}

\section{Discussão}

O presente estudo teve por objetivo investigar as possibilidades e potencialidades de diferentes jogos/ brincadeiras de bola com os pés, com a finalidade de obter informações que auxiliem pedagogicamente os treinadores no decorrer de suas sessões de treino. Os resultados mostram que cada jogo/brincadeira de bola com pés proporcionam basicamente as mesmas possibilidades técnico-táticas evidentes, independentemente de quem esteja a jogar, justificando e apontando o padrão sistêmico que organiza o jogo em ação (Scaglia, 2011, 2017; Scaglia et al., 2013). Se temos as mesmas regras e condições externas, a lógica do jogo guiará os jogadores a evidenciarem no seu jogar basicamente semelhantes possibilidades de ação. Nesse sentido, os resultados indicam que, independentemente do grupo a jogar, o Bobinho proporcionou uma maior emergência de passes e domínios, potencializando um dos princípios operacionais de ataque, a manutenção da posse de bola, a qual foi mais ou menos eficientes segundo os potenciais acertos e erros, dependentes dos diferentes grupos dos jogadores. Do mesmo modo, os jogos de Rebatida e Artilheiro estimularam uma quantidade maior de evidentes finalizações realizadas em relação ao Bobinho, potencializando outro princípio operacional de ataque (Bayer, 1994).

Nesse sentido, ainda que pertençam a mesma família (jogos de bola com os pés), cada jogo é irredutível, possuindo uma lógica interna particular (Scaglia et al., 2013; Scaglia, 2017). Logo, cada jogo exige dos seus jogadores uma capacidade de interpretação particular, potencializando e promovendo aprendizagens e adaptações específicas. Ou seja, à medida que os jogadores buscam elucidar a sua lógica particular, cada um dos jogos proporcionam a emergência de diferentes ações técnico-táticas, que ao longo do tempo vão se caracterizando como aprendizagens, à medida que vão 
gerando e estabilizando mudanças que permanecem em suas capacidades (Illeris, 2013).

Assim, foi possível verificar que o Grupo 02 (Universitários) apresentou uma quantidade maior de passes realizados do que o Grupo 01 (Crianças) no Bobinho, bem como uma maior dinâmica de troca de passes. Já os jogadores do Grupo 01 realizaram uma quantidade maior de toques bola. Já nos jogos da Rebatida, os jogadores do Grupo 02 não apresentaram a realização de disputas, enquanto que as crianças (Grupo 01) apresentaram uma quantidade maior de situações de 1x1 nestes jogos. Esses resultados evidenciam as potencialidades latentes frente às possibilidades evidentes. O passe e a disputa são possibilidades evidentes nos jogos Bobinho e Rebatida, respectivamente, porém o maior entendimento da lógica do jogo, demonstram que o Grupo 02 conseguiu lidar melhor com os constrangimentos proporcionados pelo Bobinho, potencializando uma maior eficácia de passes realizados e uma maior dinâmica na troca de passes. O mesmo aconteceu quando as crianças realizaram uma quantidade maior de disputadas no jogo da Rebatida, o que mais uma vez demonstra que, apesar de poder driblar (colocar a bola em disputa), os jogadores universitários (Grupo 02) buscaram aproveitar a superioridade numérica, justificando uma compreensão latente sobre a lógica do jogo, em que seu contexto do jogo gera, quando ocorre a rebatida, uma situação de inferioridade numérica para a defesa, sendo dois atacantes contra um defensor mais goleiro.

Outros estudos já destacaram que jogadores mais velhos e com mais experiências tendem a ter um melhor desempenho em situações de jogo. Machado et al. (2019b) observaram que jogadores mais velhos e com maior nível de desempenho tático tendem a responder melhor aos problemas de jogo que emergem em tarefas com maior nível de dificuldade. Menuchi et al.(2018), ao estudar a influência da coordenação interpessoal no bobinho, constatou que jogadores mais experientes conseguem utilizar o espaço de jogo disponível de forma mais eficiente, resultando em um comportamento mais coletivo e estável. Além disso, os autores revelaram ainda que jogadores mais jovens realizam um jogo menos elaborado, centralizando suas intenções e percepções para a bola, refletindo no desempenho em espaços mais restritos, o que poderá dificultar a realização dos passes e domínios, corroborando com os resultados acima discutidos, referentes às ações potenciais dos jogadores do Grupo 01, por exemplo.

Dando sequência a essa reflexão, as possibilidades e potencialidades que esses e todos os jogos/brincadeiras de bolas com os pés promovem, nos leva a refletir sobre a importância dos clubes e escolinhas de futebol de utilizarem estratégias que permitam criar um ambiente significativo e representativo de aprendizagem aos jogadores (Scaglia, 2014; Bettega et al., 2019; Machado et al., 2019a; Serra-Olivares \& Garcia-Rubio, 2017), proporcionando contextos desafiadores e lúdicos de prática, semelhante aos que aconteciam com maior frequência nas ruas, estimulando a criação de um vínculo afetivo entre o jogador e o jogo. Nesse sentido, tornase fundamental que estes contextos formais de prática possam proporcionar aos jogadores tarefas que respeitem os elementos-chave do futebol de rua, com o intuito de motivá-los e de estimular a aquisição de comportamentos exploratórios, potencializando aprendizagens e o desenvolvimento da inteligência e criatividade dos jogadores frente às possibilidades que o jogo oferece (Scaglia, 2014; Machado et al., 2019a).

Por fim, esses números evidenciados a partir da demonstração do processo organizacional sistêmico do jogo em ação, devem demonstrar ao professor/treinador quando sua intervenção pedagógica se faz necessária, pois apesar de basicamente os jogos/brincadeiras estudados apresentarem as mesmas possiblidades, as potencialidades latentes são dependes do nível de relação e compreensão da lógica do jogo pelo jogadores, permitindo professor/treinador saber como e quando provocar constrangimentos (manipulando possibilidades de ensino), de modo a atingir os objetivos do treino, frente ao nível da turma, objetivo do treino, planejamento e currículo preestabelecidos (Scaglia, 2014; Travassos, 2014).

Portanto, esse estudo pode ser importante para auxiliar professores/treinadores a projetarem melhor suas sessões de treino a partir de uma perspectiva da pedagogia do jogo, utilizando os jogos/brincadeiras de bola com os pés para proporcionar aos jogadores ambientes representativos de prática, potencializando a aprendizagem dos jogadores (Scaglia, 2011, 2014).

\section{Conclusão}

Com os resultados obtidos no presente estudo, foi possível avançar na compreensão de que cada um dos jogos/ brincadeiras de bola com os pés investigados apresenta basicamente as mesmas possibilidades técnico-táticas, independentemente de quem esteja a jogar. Ou seja, em ambos os grupos, o jogo de Bobinho enfatizou o conteúdo evidente de manutenção da posse de bola, por meio da troca de passes, enquanto que os jogos de Rebatida e Artilheiro enfatizaram progressão ao alvo e finalização.

Contudo, esses mesmos jogos estimulam diferentes potencialidades técnico-táticas latentes. Esta compreensão avança ao constatar que os universitários conseguiram aproveitar melhor as situações de superioridade numérica nos jogos de Rebatida, enquanto que as crianças priorizaram mais situações de $1 \times 1$ nestes jogos. Além disso, os universitários realizaram uma quantidade maior de passes e apresentaram uma maior dinâmica na troca de passes do que as crianças, indicando a necessidade de proporcionar tarefas ajustadas ao nível de desempenho técnico-tático dos jogadores.

Sendo assim, destacamos a importância de os professores/treinadores resgatarem elementos-chave do futebol de rua em suas sessões de treino, manipulando cuidadosamente os constrangimentos-chave da tarefa para enfatizar os conteúdos pretendidos e para adaptá-las aos seus jogadores. Estudos futuros podem destacar como a manipulação de diferentes constrangimentos em um mesmo jogo/brincadeira afeta o seu processo organizacional sistêmico, de modo a gerar novas possibilidades e, concomitantemente, potencializar latentes ações técnicotáticas e/ou tático-técnicas, mas sempre visando estabelecer essas adaptações pedagógicas de acordo com o nível de habilidades dos jogadores. 


\section{Referências}

Bayer, C. (1994). O ensino dos desportos coletivos. Lisboa, Portugal Dina livros.

Belozo, F.L. \& Scaglia, A. (2017). Pedagogia do Esporte: O futebol e o jogo. In: Belozo, F.L. \& Lopes, C.R. Futebol sistêmico: conceitos e metodologias de treinamento (pp. 31-47). 1. ed. Jundiaí, Brasil: Paco.

Belozo, F.L. (2015). Treinamento com jogos: a importância das regras e da dimensão dos campos nas variáveis físicas e na movimentação dos jogadores de futebol durante os treinamentos. Limeira. Dissertação (Mestrado em Nutrição, Esporte e Metabolismo, Faculdade de Ciências Aplicas, Universidade Estadual de Campinas) Retrieved from http://repositorio.unicamp.br/handle/REPOSIP/ 244488

Bettega, O.B., Machado, J.C., Scaglia, A., Marques Filhos, C.V., \& Galatti, L.R. (2019). Formar o treinador e o jogador nas categorias de base do futebol: engendrando na interação e/ou na especificidade?. Movimento (ESEFID/UFRGS), 25, 1-13.

Bettega, O.B., Scaglia, A.J., Nascimento, J., Ibáñez, S., \& Galatti, L.R. (2018). O ensino da tática e da técnica no futebol: concepção de treinadores das categorias de base. Retos, 33, 112-117.

Caldeira, P., Paulo, A., Infante, J., \& Araújo, D. (2019). A influência da pedagogia não-linear e da abordagem baseada nos constrangimentos no treino do remate no voleibol. Retos, 36, 590-596.

Chow, J.Y. (2013). Nonlinear learning underpinning pedagogy: evidence challenges and implications. Quest, 65, 469-484.

Chow, J.Y., \& Atencio, M. (2014). Complex and nonlinear pedagogy and the implications for the physical education. Sport, Education and Society, 19(8), 1034-1054

Côté, J.K.; Erickson, K.; \& Abernethy, B. (2013). Play and Practice During Childhood. In: Côté, J. \& Lidor R. Conditions of Children's Talent Development in Sport (pp.9-20). Morgantown, Estados Unidos: Fitness Information Technology.

Fabiani, D.J. (2016). O jogo no horário livre: A Educação Física na educação não formal. Campinas. Dissertação (Mestrado em Educação Física, Faculdade de Educação Física, Universidade Estadual de Campinas). Retrieved from http:// repositorio.unicamp.br/handle/REPOSIP/305339.

Ferreira, E.C. (2014). Treinamento com jogos no futebol: estudos das emergências técnicas e táticas advindas dos constrangimentos provocados pela alteração na dimensão do campo a partir de matrizes de jogos conceituais. Limeira. Dissertação (Mestrado em Nutrição, Esporte e Metabolismo, Faculdade de Ciências Aplicas, Universidade Estadual de Campinas) Retrieved from http://repositorio.unicamp.br/ handle/REPOSIP/244486.

Figueroa, P.J., Leite, N.J., \& Barros, R.M. (2003). A flexible software for tracking of markers used in human motion analysis. Computer methods and Programs in Biomedicine, 72(2), 155-165.

Fonseca, H.; Garganta, J. (2006). Futebol de rua: um beco com saída: do jogo espontâneo à prática deliberada. Lisboa, Portugal: Visão e Contextos.

Ford, P.R., Yates, I., \& Williams, A.M. (2010) An Analysis of Practice Activities and Instructional Behaviours Used by Youth Soccer Coaches During Practice: Exploring the Link Between Science and Application. Journal of Sports Sciences, 28(5), 483-495.

Ford. P.R., Ward, P., Hodges, N.J., \& Williams, A.M. (2009). The role of deliberate practice and play in career progression in sport: The early engagement hypothesis. High Ability Studies, 20 (1), 65-75

Freire, J.B. (2002). Jogo: entre o riso e o choro. Campinas, Brasil: Autores Associados.

Freire, J.B. (2003). Pedagogia do futebol. Campinas, Brasil: Autores Associados

Freire, J.B.; Scaglia, A. (2003). Educação como prática corporal. São Paulo, Brasil: Scipione.

Galatti, L.R., Reverdito, R.S., Scaglia, A.J., Paes, R.R., \& Seoane, A.M. (2014) Pedagogia do Esporte: tensão na ciência e o ensino dos Jogos Esportivos Coletivos. Revista da Educação física. 25, 153-162.

Garganta, J.; Guilherme, J.; Barreira, D.; Brito, J.; \& Rebelo, A. (2013). Fundamentos e práticas para o ensino e treino do futebol. In: Tavares, F. Jogos Desportivos Coletivos: Ensinar a jogar (pp. 199-263). Porto: Editora FADEUP.

Giddens, A. (1991). As consequências da modernidade. São Paulo, Brasil: Editora Unesp.

Grandim, G.V. (2015). Treinamento com jogos no futebol: investigações das vertentes técnicas, táticas e físicas nas matrizes de jogos. Limeira. Dissertação (Mestrado em Nutrição, Esporte e Metabolismo,
Faculdade de Ciências Aplicas, Universidade Estadual de Campinas). Retrieved from http://repositorio.unicamp.br/handle/ REPOSIP/244510.

Ibáñez, S.J. (2000). La enseñanza del baloncesto dentro del contexto educativo. Habilidad Motriz. Revista de ciencias de la actividad física y del deporte, 15, 12-21.

Ibáñez, S.J. (2002). Los contenidos de enseñanza del baloncesto en las categorías de formación. In Ibáñez, S.S. \& Macías MM (Eds.). Novos horizontes para o treino do básquetbol (pp.111-136). Cruz Quebrada, Portugal: Edições FMH, Facultade de Motricidade Humana.

Illeris, K. (2013). Uma compreensão abrangente sobre a aprendizagem humana. In Illeris, k. (Eds.). Teorias contemporâneas da aprendizagem. Porto Alegre: Penso.

Kirk, D., \& Machaphail, A. (2002). Teaching games for understanding and situated learning: Rethinking the Bunker-Thorpe model. Journal of teaching in Physical Education, 21(2), 177-192.

Leonardo, L., Scaglia, A., \& Reverdito, R.S. (2009). O ensino dos esportes coletivos: metodologia pautada na família dos jogos. Motriz: Revista de Educação Física, 15(2), 236-246.

Lizana, C. (2013). Treinamento de futebol: estudo comparativo da interferência de dois meios táticos no rendimento de jogadores de futebol em jogos conceituais. Limeira. Dissertação (Mestrado em Nutrição, Esporte e Metabolismo, Faculdade de Ciências Aplicas, Universidade Estadual de Campinas). Retrieved from http:// repositorio.unicamp.br/handle/REPOSIP/244467.

Machado, J.C., Barreira, D., Galatti, L.R., Chow, J.Y., Garganta, J., \& Scaglia AJ. (2019a). Enhancing learning in the context of Street football: a case for Nonlinear Pedagogy. Physical Education and Sport Pedagogy, 24 (2), 176-189.

Machado, J.C., Barreira, D., Teoldo, I., Travassos, B., Bosco Junior, J., Dos Santos, J.O., \& Scaglia, A. (2019b). How Does the Adjustment of Training Task Difficulty Level Influence Tactical Behavior in Soccer? Research Quarterly for Exercise and Sport, 90 (1), 1-15.

Machado, J.C.; Thiengo, C.; \& Scaglia, A. (2017). A formação do treinador de iniciação esportiva: o que é preciso aprender para ensinar futebol. In: Galatti, L.R.; Scaglia, A.; Montagner, P.C.; \& Paes, R.R. (Eds.), Pedagogia do esporte: desenvolvimento de treinadores e atletas (pp. 167-187). Campinas, Brasil: Editora da Unicamp.

Menuchi, M.R., Moro, A.R., Ambrósi, P.E., Pariente, C.A., \& Araújo, D. (2018) Effects of spatiotemporal constraints and age on the interactions of soccer players when competing for ball possession. Journal of Sports Science and Medicine,17, 379-391.

Reverdito, S.R., Scaglia, A., \& Paes, R.R. (2009). Pedagogia do esporte: panorama e análise conceitual das principais abordagens. Motriz, 15(3), 600-610.

Roca, A., Williams, A.M., \& Ford, P.R. (2012). Developmental Activities and the Acquisition of Superior Anticipation and Decision Making in Soccer Players. Journal of Sports Sciences, 30 (15), 1643-1652.

Scaglia, A. (2005). Jogo: um sistema complexo. In: Freire J.B.; Venâncio S. O jogo dentro e fora da escola (pp.37-69). Campinas, Brasil: Autores Associados.

Scaglia, A. (2011). O futebol e as brincadeiras de bola: a família dos jogos de bola com os pés. São Paulo, Brasill: Editora Phorte.

Scaglia, A. (2014). Pedagogia do futebol: construindo um currículo de formação para iniciação ao futebol em escolinhas. In: Picollo, V. \& Toledo, E. Abordagens Pedagógicas do Esporte: modalidades convencionais e não convencionais (pp. 16-67). Campinas, Brasil: Papirus.

Scaglia, A. (2014b). A pedagogia do esporte e as novas tendências metodológicas. Nova Escola, 29, 84-86.

Scaglia, A. (2017) Pedagogia do jogo: o processo organizacional dos jogos esportivos coletivos enquanto modelo metodológico para o ensino. Revista Portuguesa de Ciências do Desporto, 17, 23-38.

Scaglia, A.J., Reverdito, S.R., Leonardo, R.L., \& Lizana, C.J. (2013). O ensino dos jogos esportivos coletivos: as competências essenciais e a lógica do jogo em meio ao processo organizacional sistêmico. Movimento, 19(4), 227-249.

Serra-Olivares, J., Garcia-Rubio, J. (2017). La problemaìtica taìctica, clave en el disenbo representativo de tareas desde el enfoque de la pedagogiì no lineal aplicada al deporte. Retos, 32, 270-278.

Sierra-Díaz, M.J., González-Víllora S., Pastor-Vicedo, J.C., \& LópezSánchez, G.F. (2019). Can We Motivate Students to Practice Physical Activities and Sports Through Models-Based Practice? A Systematic Review and Meta-Analysis of Psychosocial Factors Related to Physical Education. Front. Psychol, 10, 1-24.

Travassos, B. (2014). A tomada de decisão no futsal. Lisboa, Portugal: Prime Books. 